\section{Science and Existence}

Two Ways of Knowing. By Alan Richardson. (Technies and Purpose, No. 1.) Pp. 30.

Scientific and Technological Education

By Edwin Barker. (Technics and Purpose, No. 2.) Pp. 37.

Technical Education

By H. A. Warren. (Technics and Purpose, No. 3.) Pp. 37.

\section{Purpose in Teacher Training}

By Monica Wingate. (Technics and Purpose, No. 4.) Pp. 38.

(London : S.C.M. Press, Ltd., 1957.) Each 2s. 6d. net.

$7 \mathrm{HE}$ British Council of Churches is sponsoring $a$ series of booklets to examine the issues arising out of the growth of science in society and the rapid expansion of technological education, particularly in relation to the purposes and values involved in the light of the Christian faith. For several years a working party convened by the Education Department of the British Council of Churches, under the chairmanship of Sir John Wolfenden, vice-chancellor of the University of Reading, has been meeting to consider some of the issues involved; it has now asked certain individuals to take responsibility for bringing together some of the views expressed in discussion. In the first booklet Prof. Alan Richardson, of the University of Nottingham, distinguish $\rightarrow s$ with great clarity between 'scientific' and 'existential' knowledge. The narrowness of scientific and technological education is examined by Edwin Barker, assistant general secretary of the National Council of the Young Men's Christian Association, in the second booklet, while in the third, H. A. Warren, principel of the South-East London Technical College, describes the system and scope of technical education in England and Wales and makes an appraisal of some of its social and cultural effects. In the fourth booklet, Monica Wingate, principal of Balls Park Training College, searches out the purpose in teacher-training with irresistible persuasiveness; her readers might have been even more sympathetic if she had first made sure that they were aware of the ways in which teachers are trained in Britain's training colleges. Before other booklets in this series are produced, more thought might be given to the purpose behind each and to make this clear in a preface ; the sequence in which they are issued should also be examined.

T. H. HaWkrNs

\section{Malayan Orchid Hybrids}

By M. R. Henderson and G. H. Addison. Pp. iv + 191. (Singapore: Government Printer, 1956.) 21 Malayan dollurs.

LTHOUGH there is such a wealth of orchid A hybrids available for cultivation in temperate countries, many of these are not happy when grown under tropical conditions. Successful efforts have therefore been made in recent years to develop hybrids within other orchid genera which are better suited to the tropics. These include the genus Dendrobium (particularly the section Ceratobium), the climbing orchids of the Vanda-Arachnis group, the strap-leaved Vanda species and Spathoglottis. The chief two centres in which this hybridization has been carried out are Malaya and the Hawaiian Islands. The present book aims at providing photographic illustrations of the more important and beautiful hybrids which have been raised, or are commonly cultivatod, in Singapore.

For most varieties dealt with there are photographs of a single flower and of a complete inflorescence. These photographs reach a high standard and are excellently reproduced on art paper. Accompanying them are brief texts which include information about parentage and place of origin as well as short descriptions and notes on cultivation. Wellillustrated and concise accounts of the cultivation in Singapore of the main groups of hybrids precede each section of the book.

Orchid growers in Malaya and in the neighbouring countries will welcome this book and it will be of value to growers in other tropical regions. It will also serve to stabilize the nomenclature of these hybrids, to which additions are continually being made. Altogether the authors are to be congratulated on the production of a useful as well as very attractive book.

\section{A Glossary of Mycology}

By Walter H. Snell and Esther A. Dick. Pp. xxxi 171 (15 plates). (Cambridge, Mass. : Harvard University Press; London: Oxford University Press, 1957.) 40s. net.

YCOLOGY, like all other sciences, has developed V its own shorthand terms to describe the diversity of form, substance and function of fungal organisms. The present volume describes nearly seven thousand such terms, and, apart from the names of colours and certain words used in general botany, most have no meaning outside this science. This number of words is almost enough, in a simpler context, to found a language; have we too many of them ? The majority save quite lengthy explanations, and so are justified as shorthand. A considerable number apply only in special parts of mycology, but this serves to indicate fungal complexity rather than redundant verbiage. A few terms, now obsolete but used in earlier literature, have historical value. A minute minority are colloquial. Colour names link those in the authoritative but relatively inaccessible "Repertoire de Couleurs" with other and more available specifications. Fifteen very clear line blocks by Henry A. C. Jackson elucidate many terms. The authors have, in all, performed a most necessary service, and have done it in a most scholarly manner. J. Grainger

\section{The Life of the Shrew}

By Dr. Peter Croweroft. Pp. vi +166. (London : Max Reinhardt, Ltd., 1957.) 15s. net.

THIS is an excellent account of the biology of the species of British shrews, with perhaps more emphasis on the common and pigmy shrews. Their general behaviour, fighting propensities, reproduction, activity rhythm and foeding, their longevity (or should it be brevity ?) and their position both as predators and prey are all dealt with. Much is the result of the author's own observations and experiments; but all the previously known facts have been incorporated in a very readable book. The shrew's reputation in folk-lore and in naturalists' accounts, even as late as 1911, is shown to be largely erroneous. The gaps in our knowledge and the methods by which they may be filled are dealt with in a stimulating and attractive manner. There are a good bibliography and index, while the tailpieces by Erik Thorn portray the characteristic postures and behaviour of shrews most admirably.
H. R. HEWER 